\title{
Genotype-phenotype correlations in pediatric patients with myotonic dystrophy type 1
}

Hyeong Jung Kim, MD, Ji-Hoon Na, MD, Young-Mock Lee, MD, PhD

Department of Pediatrics, Yonsei University College of Medicine, Seoul, Korea

Purpose: Myotonic dystrophy, also known as dystrophia myotonica (DM), is an autosomal dominant disorder with 2 genetically distinct forms. DM type 1 (DM1) is the more common form and is caused by abnormal expansion of cytosine/thymine/guanine (CTG) repeats in the DM protein kinase (DMPK) gene. Our study aimed to determine whether the age of onset is correlated with CTG repeat length in a population of pediatric patients with DM1.

Methods: We retrospectively identified 30 pediatric patients with DM1 that underwent DMPKtesting, of which the clinical data of 17 was sufficient. The cohort was divided into 2 subgroups based on the clinical phenotype (congenital-onset vs. late-onset) and number of CTG repeats ( $<1,000$ vs. $\geq 1,000)$.

Results: We found no significant difference between the age of onset and CTG repeat length in our pediatric patient population. Based on clinical subgrouping, we found that the congenital-onset subgroup was statistically different with respect to several variables, including prematurity, rate of admission to neonatal intensive care unit, need for respiratory support at birth, hypotonia, dysphagia, ventilator dependence, and functional status on last visit, compared to the late-onset subgroup. Based on genetic subgrouping, we found a single variable (poor feeding in neonate) that was significantly different in the large CTG subgroup than that in the small CTG subgroup.

Conclusion: Clinical variables exhibiting statistically significant differences between the subgroups should be focused on prognosis and designing tailored management approaches for the patients; our findings will contribute to achieve this important goal for treating patients with DM1.

Key words: Myotonic dystrophy type 1, Genotype, Phenotype, CTG repeat, Age of onset

\section{Introduction}

Myotonic dystrophy (also known as dystrophia myotonica; DM) is an autosomal dominant disorder characterized by muscular dystrophy, myotonia, cataract, hypogonadism, and cardiac conduction disorders. It is classified into 2 types, DM type 1 (DM1) and DM type 2 (DM2), based on the causative genetic mutation ${ }^{1)}$; DM1 is more severe and common with an estimated prevalence of 1 in 8,000. ${ }^{2,3)}$

Although diagnosis can be made on the basis of several symptoms, it is often difficult to confirm the diagnosis, solely based on clinical symptoms, in mild cases. ${ }^{4)}$ For such instances, direct analysis of the cytosine/thymine/guanine (CTG) trinucleotide repeat in the 3' untranslated region of myotonic dystrophy protein kinase (DMPK) gene on chromosome 19 by Southern blotting enables a reliable diagnosis, ${ }^{5)}$ since DM1 is known to result from an abnormal number of CTG repeats. ${ }^{2,6)}$

Severity of DM1 varies with the number of CTG repeats. ${ }^{6,7)}$ While mildly affected patients have 50-150 repeats, patients with classic DM1 have 100-1,000 repeats, and those with the congenital form of the disease have $>2,000$ repeats. ${ }^{2,89}$ However, due to insufficient number of
Corresponding author: Young-Mock Lee, MD, PhD Department of Pediatrics, Yonsei University College of Medicine, 211 Eonju-ro, Gangnam-gu, Seoul 06273, Korea

Tel: +82-2-2019-3350

Fax: +82-2-2019-4881

E-mail:ymleemd@yuhs.ac

https://orcid.org/0000-0002-5838-249X

Received: 28 August, 2018

Revised: 18 September, 2018

Accepted: 20 September, 2018
Copyright (C) 2019 by The Korean Pediatric Society

This is an open-access article distributed under the terms of the Creative Commons Attribution NonCommercial License (http://creativecommons.org/ licenses/by-nc/4.0/) which permits unrestricted noncommercial use, distribution, and reproduction in any medium, provided the original work is properly cited. 
patients, investigation of various hypotheses regarding diagnostic tools and treatment of DM1 has been limited. In fact, there is currently no established cutoff value or classification standard for the distribution of patients, genetically diagnosed with DM1, according to CTG repeat length.

Thus, our aim was to determine whether a correlation between severity of clinical phenotype and length of the CTG repeat region could be established for better classification of the disease in affected individuals.

\section{Materials and methods}

\section{Patient group}

We identified 30 patients with DM1, who were followed up in 2 centers of our hospital (Gangnam Severance Hospital and Severance Children's Hospital), through a retrospective study (Fig. 1). All participants were diagnosed with DM1 by genetic testing of DMPK from November 2005 to June 2017. Thirteen patients were excluded from the study due to poor clinical data. Our final cohort of 17 patients with DM1 had sufficient clinical data, including clinical symptoms, age of onset, previous history, length of CTG repeat, laboratory and radiological findings, and follow-up data. Institutional Review Board, Gangnam Severance Hospital, Yonsei University College of Medicine (approval number: 3-2017-0263) and written informed consent was obtained from the parents or legal guardians of all patients.

\section{Subgroup analysis}

We derived 2 different sets of subgroups for intergroup comparison based on 2 criteria, clinical and genetic. In clinical subgrouping, patients were classified based on the onset time of symptoms; the ones whose symptoms appeared within one month formed the congenital-onset subgroup while the others with later onset of symptoms formed the late-onset subgroup. In genetic subgrouping, patients were classified based on the number of CTG repeats. The "Large

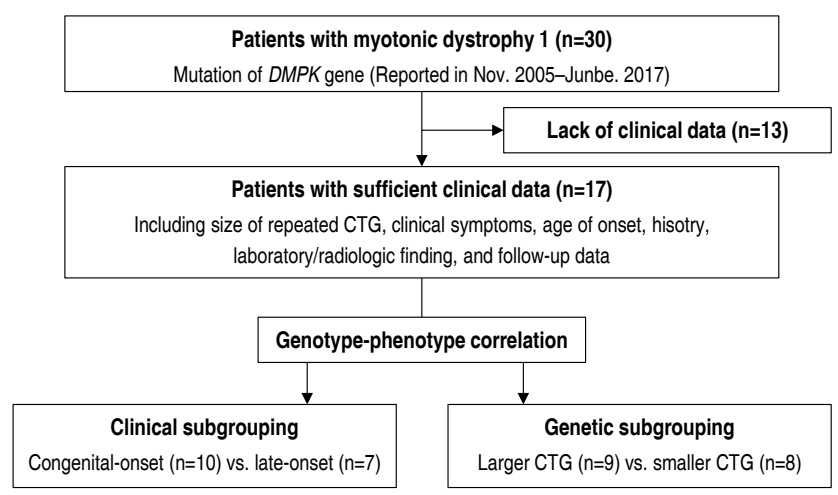

Fig. 1. Subgroup analysis of patients with myotonic dystrophy. CTG, cytosine/thymine/guanine.
CTG" subgroup included individuals with $>1,000$ CTG repeats while the "small CTG" subgroup consisted of individuals with $<1,000$ CTG repeats. Currently, the most widely known classification of disease severity based on CTG repeats is as follows: normal individuals (537 repeats), mildly affected patients (50-150 repeats), patients with classic DM1 (100-1,000 repeats), and patients with congenital DM1 (>2,000 repeats). As stated earlier, there is no established cutoff value or classification standard for the distribution of the patients according to CTG repeat length, especially over 1,000-2,000 repeats. Since $23 \%$ of patients had congenital DM1, possessing 1,000-2,000 repeats of the CTG trinucleotide, in our patient group, we set $>1,000$ repeats as the threshold for classification of congenital DM1 in our cohort.

\section{Statistics}

All analyses were conducted using IBM SPSS Statistics ver. 20.0 (IBM Co., Armonk, NY, USA). We used Fisher exact test to calculate $P$ values between each set of subgroups. Spearman rank correlation was used to identify whether there was a relationship between length of the CTG repeat region and age of onset, whereas the MannWhitney $U$ test was used to compare time periods between birth, symptom onset, and diagnosis. A $P$ value of $<0.05$ was considered statistically significant.

Table 1. Demographic characteristics of patients with myotonic dystrophy $(\mathrm{n}=17)$

\begin{tabular}{lr}
\hline Variable & \multicolumn{1}{c}{ Value } \\
\hline Sex & $12(70.6)$ \\
Male & $5(29.4)$ \\
Female & $4.1 \pm 5.8$ \\
Time period between birth, symptom onset, and genetic diagnosis (yr) \\
From birth to symptom onset & $1.6 \pm 2.7$ \\
From symptom onset to diagnosis & $5.7 \pm 7.3$ \\
From birth to diagnosis & \\
Age of onset & $10(58.8)$ \\
Neonate (<1 mo) & $7(41.2)$ \\
Infant and older ( $\geq 1$ mo) & $1 / 7(14.3)$ \\
$\quad<5$ yr & $3 / 7(42.9)$ \\
$5-10$ yr & $3 / 7(42.9)$ \\
$10-15$ yr & \\
CTG repeat length & $5(29.4)$ \\
$100-500$ & $3(17.6)$ \\
$500-1,000$ & $4(23.5)$ \\
$1,000-2,000$ & $5(29.4)$ \\
$\geq 2,000$ & \\
\hline
\end{tabular}

Values are presented as number (\%) or mean \pm standard deviation.

CTG, cytosine/thymine/guanine. 


\section{Results}

\section{Demographics}

Our cohort consisted of 12 male (70.6\%) and 5 female patients (29.4\%) (Table 1). The time period from diagnosis to onset of symptoms was $1.6 \pm 2.7$ years, and that from birth to onset was $4.1 \pm$ 5.8 years. Ten patients were found to have congenital-onset DM1 whose symptoms manifested within 1 month from birth, 7 were found to be late-onset patients whose symptoms manifested after 1 month from birth. We observed a varied distribution in the number of patients classified according to CTG trinucleotide repeat length, but there was no correlation between age of onset and length of CTG repeat in our pediatric patient population. However, there was a nonsignificant tendency towards an inverse relationship on scatter

Table 2. General characteristics and clinical manifestations of patients with myotonic dystrophy based on clinical subgrouping $(n=17)$

\begin{tabular}{lccc}
\hline Variable & $\begin{array}{c}\text { Congenital-onset } \\
(\mathrm{n}=10)\end{array}$ & $\begin{array}{c}\text { Late-onset } \\
(\mathrm{n}=7)\end{array}$ & $P$ value \\
\hline Sex & & & \\
$\quad$ Male & $6(60.0)$ & $6(85.7)$ & 0.278 \\
$\quad$ Female & $4(40.0)$ & $1(14.3)$ & 0.278 \\
First symptom & & \\
$\quad$ Hypotonia & $10(100)$ & $0(0)$ & $<0.001$ \\
Myotonia & $0(0)$ & $2(28.6)$ & 0.154 \\
Weakness & $0(0)$ & $1(14.3)$ & 0.412 \\
Delayed development & $0(0)$ & $2(28.6)$ & 0.154 \\
Gait disturbance & $0(0)$ & $1(14.3)$ & 0.412 \\
Chest discomfort & $0(0)$ & $1(14.3)$ & 0.412
\end{tabular}

Birth history

Prenatal

Decreased fetal movements $\quad 2 / 9(22.2) \quad 0 / 3(0) \quad 0.545$

$\begin{array}{llll}\text { Polyhydramnios } & 2 / 9(22.2) & 0 / 3(0) & 0.545\end{array}$

At birth

Prematurity

$\begin{array}{llll}\text { Preterm } & 6(60.0) & 0 / 7(0) & 0.035\end{array}$

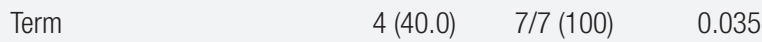

IUP

Less than 34 wk $(<34 w k) \quad 2(20.0) \quad 0(0) \quad 0.331$

Between 34 wk and 37 wk $\quad 5(50.0) \quad 0(0) \quad 0.044$

More than 37 wk $(\geq 37 w k) \quad 3(30.0) \quad 7(100) \quad 0.010$

Birth weight

$\begin{array}{lclc}\text { ELBW }(<1,000 \mathrm{~g}) & 0(0) & 0 / 5(0) & - \\ \operatorname{VLBW}(<1,500 \mathrm{~g}) & 0(0) & 0 / 5(0) & - \\ \text { LBW }(<2,500 \mathrm{~g}) & 5(50.0) & 0 / 5(0) & 0.084 \\ \text { Normal }(\geq 2,500 \mathrm{~g}) & 5(50.0) & 5 / 5(100) & 0.084 \\ \text { IUGR } & 2(20.0) & 0 / 5(0) & 0.429 \\ \text { Perinatal asphyxia } & 7(70.0) & 0 / 3(0) & 0.070 \\ \text { NICU admission } & 10(100) & 0 / 3(0) & 0.003 \\ \text { Need for respiratory support } & 9(90.0) & 0 / 3(0) & 0.014\end{array}$

plot (Correlation coefficient=-0.194, $P=0.384$ ).

\section{Clinical subgrouping}

1) General characteristics and clinical manifestations

As shown in Table 2, among our clinically derived subgroups, the sex ratio was 6 male (60.0\%) to 4 female patients (40.0\%) in the congenital-onset subgroup and 6 male (85.7\%) to 1 female patient (14.3 $\%$ ) in the late-onset subgroup. This difference in sex distribution was, however, not statistically significant. The first symptom to manifest

Table 2. General characteristics and clinical manifestations of patients with myotonic dystrophy based on clinical subgrouping $(n=17)$ (Contiuned)

\begin{tabular}{ccc}
\hline Variable & $\begin{array}{c}\text { Congenital-onset } \\
(n=10)\end{array}$ & $\begin{array}{c}\text { Late-onset } \\
(n=7)\end{array}$
\end{tabular}$\quad P$ value

Family history

History of muscular disease $\quad 6(60.0) \quad 4(57.1) \quad 0.646$

Time period between birth, symptom onset, and genetic diagnosis (yr)

$\begin{array}{lllr}\text { From birth to symptom onset } & 0.1(0.1-0.1) & 9.9(1.2-14.9) & <0.001 \\ \text { From symptom onset to diagnosis } & 0.1(0.1-1.7) & 2.0(0.1-10.5) & 0.007\end{array}$

From birth to diagnosis $\quad 0.1(0.1-1.7) 15.0(4.5-20.4)<0.001$

Systemic involvements

Head and neck

Cataract

$0 / 10(0) \quad 1 / 7(14.3) \quad 0.412$

Cardiac

$\begin{array}{lll}\text { Arrhythmia } & 0 / 10(0) & 1 / 7(14.3)\end{array}$

Gastrointestinal

Poor feeding in neonate $\quad$ 8/10 (80.0) $\quad 2 / 7(28.6) \quad 0.052$

Dysphagia $\quad 8 / 10(80.0) \quad 1 / 7(14.3) \quad 0.015$

Intestinal pseudo-obstruction $\quad 0 / 10(0) \quad 0 / 7(0)$

Cholelithiasis $\quad 0 / 10(0) \quad 0 / 7(0)$

Respiratory

$\begin{array}{llll}\text { Congenital respiratory distress } \quad 6(60.0) & 0(0) & 0.035\end{array}$

Muscular

Hypotonia in neonate $\quad 10(100) \quad 1(14.3) \quad<0.001$

Myotonia

Weakness

$4 / 4(100) \quad 5 / 5(100)$

Myotonic discharges on EMG $\quad 1 / 1(100) \quad 2 / 5(40.0) \quad 0.500$

Neurologic

Delayed development or MR $\quad 5 / 6(83.3) \quad 5 / 7(71.4) \quad 0.563$

CTG repeat length (n)

$100-500$

$3(30.0) \quad 2(28.6) \quad 0.686$

$500-1,000 \quad 1(10.0) \quad 2(28.6) \quad 0.360$

$\begin{array}{llll}1,000-2,000 & 4(40.0) & 0(0) & 0.088\end{array}$

$\begin{array}{llll}\geq 2,000 & 2(20.0) & 3(42.9) & 0.314\end{array}$

Values are presented as number (\%) or median (range).

IUP, intrauterine pregnancy; ELBW, extremely low birth weight; VLBW, very low birth weight; LBW, low birth weight; IUGR, intrauterine growth restriction; NICU, neonatal intensive care unit; EMG, electromyogram; MR, mental retardation; CTG, cytosine/thymine/guanine. 
in cases with DM1, though variable, included hypotonia, myotonia, weakness, delayed development, gait disturbance, and chest discomfort. We found a significant difference in the occurrence of hypotonia between patients from our clinical subgroups; hypotonia occurred in all patients from the congenital-onset subgroup while it was not at all reported in the late-onset subgroup. Furthermore, we found that birth and family history, including prematurity, neonatal intensive care unit (NICU) admission rate, and need for respiratory support, was significantly dominant in the congenital-onset subgroup compared to those in the late-onset subgroup. Prematurity occurred in $60.0 \%$ of patients from the congenital-onset subgroup while it occurred in none in the late-onset subgroup ( $P=0.035)$; the proportion of NICU admission and need for respiratory support (100\% and 90.0\%, respectively) in the congenital-onset subgroup was high compared to none in the late-onset subgroup $(P=0.003$ and $P=0.014$, respectively). On the other hand, prenatal history, such as decreased fetal movements and polyhydramnios, had no statistically significant difference between the subgroups. We also found that the involved systems were variable and 4 clinical symptoms, specifically poor feeding in neonate, dysphagia, congenital respiratory distress, and hypotonia in neonate, were statistically more frequent in the congenital-onset subgroup, with frequencies of 80.0\%, 80.0\%, $60.0 \%$, and 100\%, respectively. Furthermore, CTG repeat distribution in congenital- and late-onset subgroups was not significantly different for patients with >2,000 CTG repeats (20.0\% vs. 42.9\%, respectively), 1,000-2,000 CTG repeats (40.0\% vs. 0\%, respectively), 500-1,000 CTG repeats (10.0\% vs. $28.6 \%$, respectively), and 100-500 CTG repeats (30.0\% vs. 28.6\%, respectively).

Table 3. Diagnostic evaluation and functional status of patients with myotonic dystrophy on the last visit based on clinical subgrouping $(n=17)$

\begin{tabular}{lccc}
\hline Variable & $\begin{array}{c}\text { Congenital-onset } \\
(n=10)\end{array}$ & $\begin{array}{c}\text { Late-onset } \\
(n=7)\end{array}$ & $P$ value \\
\hline CK level $(n=16)$ & & & \\
$\quad$ Elevated & $4(40.0)$ & $1 / 6(16.7)$ & 0.346 \\
Brain MRI findings ( $\mathrm{n}=11)$ & & & \\
$\quad$ Normal & $1 / 7(14.3)$ & $2 / 4(50.0)$ & 0.279 \\
Abnormal & $6 / 7(85.7)$ & $2 / 4(50.0)$ & - \\
$\quad$ Signal changes of white matter & $4 / 7(57.1)$ & $1 / 4(25.0)$ & 0.348 \\
$\quad$ Atrophy of brain parenchyme & $2 / 7(28.6)$ & $1 / 4(25.0)$ & 0.721 \\
Need for respiratory support $(n=17)$ & & & \\
$\quad$ Independent & $5(50.0)$ & $7(100)$ & 0.044 \\
Dependent on ventilator & $5(50.0)$ & $0(0)$ & 0.044 \\
Activities of daily life $(n=17)^{\star}$ & & & \\
Mild & $4(40.0)$ & $7(100)$ & 0.035 \\
$\quad$ Moderate & $2(20.0)$ & $0(0)$ & 0.331 \\
Severe & $4(40.0)$ & $0(0)$ & 0.103 \\
\hline
\end{tabular}

Values are presented as number (\%).

CK, creatinine kinase; MRI, magnetic resonance imaging.

*Mild: ambulatory and/or independent, moderate: WC and/or partially dependent, severe: bed-ridden and/or totally dependent.
2) Diagnostic evaluation and functional status in the last visit Although 31.3\% of all patients showed increased creatinine kinase (CK), there was no significant difference between the 2 subgroups (Table 3). In addition, abnormal findings in brain MRI were more common in the congenital-onset subgroup compared to that in the late-onset subgroup (85.7\% vs. 50.0\%, respectively), though not statistically significant. In the last out-patient follow-up visit, dependence on ventilator was higher in the congenital-onset subgroup compared to that in the late-onset subgroup (50.0\% vs. $0 \%$, respectively), whereas the late-onset subgroup had fewer limits (in the mild form) on daily life.

Table 4. General characteristics and clinical manifestations of patients with myotonic dystrophy based on genetic subgrouping $(n=17)$

\begin{tabular}{llll}
\hline Variable & $\begin{array}{c}\text { Large CTG } \\
(\mathrm{n}=9)\end{array}$ & $\begin{array}{c}\text { Small CTG } \\
(\mathrm{n}=8)\end{array}$ & $P$ value \\
\hline $\begin{array}{llll}\text { Sex } \\
\quad \text { Male }\end{array}$ & & \\
$\quad \begin{array}{l}\text { Female } \\
\text { First symptom }\end{array}$ & $3(75.7)$ & $2(25.0)$ & 0.563 \\
$\quad$ Hypotonia & & & \\
Myotonia & $6(66.7)$ & $4(50.0)$ & 0.419 \\
Weakness & $0(0)$ & $2(25.0)$ & 0.206 \\
Delayed development & $0(0)$ & $1(12.5)$ & 0.471 \\
Gait disturbance & $2(22.2)$ & $0(0)$ & 0.265 \\
Chest discomfort & $1(11.1)$ & $0(0)$ & 0.529 \\
& $0(0)$ & $1(12.5)$ & 0.471
\end{tabular}

Birth history

Prenatal

$\begin{array}{llll}\text { Decreased fetal movements } & 1 / 6(16.7) & 1 / 6(16.7) & 0.773 \\ \text { Polyhydramnios } & 0 / 6(0) & 2 / 6(33.3) & 0.227 \\ \text { At birth } & & & \end{array}$

Prematurity

Preterm

Term

$5(55.6)$

$1(12.5)$

0.088

IUP

Less than 34 wk (<34 wk)

4 (44.4)

7 (87.5)

0.088

Between 34 wk and 37 wk

1 (11.1)

$1(12.5)$

0.735

More than $37 w k$ ( $\geq 37 w k$ )

4 (44.4)

$1(12.5)$

0.183

Birth weight

$\operatorname{ELBW}(<1,000 \mathrm{~g})$

4 (44.4)

$6(75.0)$

0.218

$\operatorname{VLBW}(<1,500 \mathrm{~g})$

$0 / 8(0)$

$0 / 7(0)$

LBW (<2,500 g)

$0 / 8(0)$

$0 / 7(0)$

Normal $(\geq 2,500 \mathrm{~g})$

$4 / 8(50.0)$

$1 / 7(14.3)$

0.182

IUGR

$4 / 8(50.0)$

6/7 (85.7)

0.182

Perinatal asphyxia

$2 / 8(25.0)$

$0 / 7(0)$

0.267

NICU admission

$4 / 8(50.0)$

$3 / 5(60.0)$

0.587

Need for respiratory support

$4 / 5(80.0)$

0.685

$6 / 8(75.0)$

$3 / 5(60.0)$ 
Table 4. General characteristics and clinical manifestations of patients with myotonic dystrophy based on genetic subgrouping $(n=17)$ (Continued)

\begin{tabular}{|c|c|c|c|}
\hline Variable & $\begin{array}{l}\text { Large CTG } \\
\quad(n=9)\end{array}$ & $\begin{array}{c}\text { Small CTG } \\
(n=8)\end{array}$ & $P$ value \\
\hline \multicolumn{4}{|l|}{ Family history } \\
\hline History of muscular disease & $6(66.7)$ & $4(50.0)$ & 0.419 \\
\hline \multicolumn{4}{|l|}{$\begin{array}{l}\text { Period between birth, symptom } \\
\text { onset, and genetic diagnosis (yr) }\end{array}$} \\
\hline From birth to symptom onset & $0.1(0.1-9.9)$ & $4.3(0.1-14.9)$ & 0.321 \\
\hline From symptom onset to diagnosis & $0.1(0.1-10.5)$ & $0.85(0.1-2.0)$ & 0.606 \\
\hline From birth to diagnosis & $0.1(0.1-20.4)$ & $5.35(0.1-16.2)$ & 0.139 \\
\hline \multicolumn{4}{|l|}{ Systemic involvements } \\
\hline \multicolumn{4}{|l|}{ Head and neck } \\
\hline Cataract & $0(0)$ & $1(12.5)$ & 0.471 \\
\hline \multicolumn{4}{|l|}{ Cardiac } \\
\hline Arrhythmia & $0(0)$ & $1(12.5)$ & 0.471 \\
\hline \multicolumn{4}{|l|}{ Gastrointestinal } \\
\hline Poor feeding in neonate & $8(88.9)$ & $2(25.0)$ & 0.015 \\
\hline Dysphagia & $6(66.7)$ & $3(37.5)$ & 0.238 \\
\hline Intestinal pseudo-obstruction & $0(0)$ & $0(0)$ & - \\
\hline Cholelithiasis & $0(0)$ & $0(0)$ & - \\
\hline \multicolumn{4}{|l|}{ Respiratory } \\
\hline Congenital respiratory distress & $4(44.4)$ & $2(25.0)$ & 0.373 \\
\hline \multicolumn{4}{|l|}{ Muscular } \\
\hline Hypotonia in neonate & $7(77.8)$ & $4(50.0)$ & 0.247 \\
\hline Myotonia & $3 / 3(100)$ & 6/6 (100) & - \\
\hline Weakness & $4 / 5(80.0)$ & $7 / 7(100)$ & 0.417 \\
\hline Myotonic discharges on EMG & $1 / 1(100)$ & $2 / 5(40.0)$ & 0.088 \\
\hline \multicolumn{4}{|l|}{ Neurologic } \\
\hline Delayed development or MR & $5 / 5(100)$ & $5(62.5)$ & 0.196 \\
\hline \multicolumn{4}{|l|}{ Age of onset } \\
\hline Neonate (<1 mo) & $6(66.7)$ & $4(50.0)$ & 0.419 \\
\hline Infant and older ( $\geq 1$ mo) & $3(33.3)$ & $4(50.0)$ & 0.419 \\
\hline$<5 \mathrm{yr}$ & $1(11.1)$ & $0(0)$ & 0.529 \\
\hline $5-10 \mathrm{yr}$ & $2(22.2$ & $1(12.5)$ & 0.547 \\
\hline $10-15 y r$ & $0(0)$ & $3(37.5)$ & 0.082 \\
\hline
\end{tabular}

Values are presented as number (\%) or mean (range).

IUP, intrauterine pregnancy; ELBW, extremely low birth weight; VLBW, very low birth weight; LBW, low birth weight; UUG, intrauterine growth restriction; NICU, neonatal intensive care unit; EMG, electromyogram; MR, mental retardation.

\section{Genetic subgrouping}

\section{1) General characteristics and clinical manifestations}

As shown in Table 4, there were 6 male (66.7\%) and 3 female patients (33.3\%) in the large CTG subgroup and 6 males (75.0\%) and 1 female (25.0\%) in the small CTG subgroup. This gender difference was, however, not statistically significant. In contrast to our findings from clinical subgrouping, we found no significant difference between the genetic subgroups for hypotonia as a first symptom, prematurity, NICU admission rate, need for respiratory support,
Table 5. Diagnostic evaluation and functional status of patients with myotonic dystrophy on the last visit based on genetic subgrouping $(n=17)$

\begin{tabular}{lccc}
\hline Variable & $\begin{array}{c}\text { Large CTG } \\
(\mathrm{n}=9)\end{array}$ & $\begin{array}{c}\text { Small CTG } \\
(\mathrm{n}=8)\end{array}$ & P value \\
\hline CK level $(\mathrm{n}=16)$ & & & \\
$\quad$ Elevated & $3 / 8(37.5)$ & $2 / 8(25.0)$ & 0.500 \\
Brain MRI findings $(\mathrm{n}=11)$ & & & \\
$\quad$ Normal & $1 / 5(20.0)$ & $2 / 6(33.3)$ & 0.576 \\
Abnormal & $4 / 5(80.0)$ & $4 / 6(66.7)$ & \\
$\quad$ Signal changes of white matter & $2 / 5(40.0)$ & $3 / 6(50.0)$ & 0.608 \\
$\quad$ Atrophy of brain parenchyme & $2 / 5(40.0)$ & $1 / 6(16.7)$ & 0.424 \\
Need for respiratory support $(\mathrm{n}=17)$ & & & \\
$\quad$ Independent & $6(66.7)$ & $6(75.0)$ & 0.563 \\
Dependent on ventilator & $3(33.3)$ & $2(25.0)$ & 0.563 \\
Limitations in daily life $(\mathrm{n}=17)^{*}$ & & & \\
$\quad$ Mild & $5(55.6)$ & $6(75.0)$ & 0.373 \\
$\quad$ Moderate & $1(11.1)$ & $1(12.5)$ & 0.735 \\
$\quad$ Severe & $3(33.3)$ & $1(12.5)$ & 0.335 \\
\hline
\end{tabular}

Values are presented as number (\%).

CTG, cytosine/thymine/guanine; CK, creatinine kinase; MRI, magnetic resonance imaging.

*Mild, ambulatory and/or independent; moderate, WC and/or partially dependent; severe, bed-ridden and/or totally dependent.

and several other clinical symptoms. We found hypotonia as a first symptom in 66.7\% of patients from the large CTG subgroup and in $50.0 \%$ of patients from the small CTG subgroup, whereas the proportion of premature birth was 55.6\% in the large CTG subgroup versus $12.5 \%$ in the small CTG subgroup. The proportion of cases requiring NICU admission and need for respiratory support was both 75.0\% in the large CTG subgroup compared to $80.0 \%$ and $60.0 \%$, respectively, in the small CTG subgroup. Poor feeding in neonate was found to be the only symptom that was significantly increased in patients in the large CTG subgroup, compared to that found in the small CTG subgroup (88.9\% vs. $25.0 \%$ respectively, $P=0.015$ ).

\section{2) Diagnostic evaluation and functional status in the last visit}

Similar to our findings from clinical subgroups, we found no significant difference in CK level and abnormal findings from brain MRI between the 2 genetically defined subgroups (Table 5). Increased CK levels of 37.5\% and 25.0\% were found in the large CTG and small CTG subgroups respectively; we also found that $80.0 \%$ and $66.7 \%$ of patients from these 2 subgroups had abnormal findings in brain MRI. Similarly, we found no significant difference between the genetic subgroups based on ventilator dependence (33.3 \% vs. $25.0 \%$, respectively) and quality of daily life (55.6\% vs. $75.0 \%$, respectively).

\section{Discussion}

Patients with DM1 do not always present typical symptoms of the 
disease, but may show variable symptoms and severities. Variable instability of a CTG trinucleotide repeat in DMPK causes genotypic and phenotypic variation. ${ }^{10)}$ Some studies have included patients with motor impairments and most patients may have several clinical features like myotonia, muscular weakness, and family history. ${ }^{10,11)}$ We found variable symptoms in our study cohort as well. However, there have been few studies that subgrouped patients according to age of onset to compare prominent clinical features between groups. One study divided patients into 5 clinical categories (congenital, infantile, juvenile, adult-onset, and late-onset) and found that muscle weakness typically arises earlier in the congenital group, whereas myotonia was the earliest prominent symptom in patients from the infantile group. Early cardiac defects were prominent in juvenile group, whereas secondary symptoms, such as cataract and endocrine disorders, were prominent in the adult-onset group. ${ }^{12)}$ Based on clinical characteristics, we divided our study cohort into 2 groups, congenital-onset and late-onset, and found that there were several variables with statistically significant differences between these 2 cohorts.

In our study, prematurity, NICU admission rate, need for respiratory support, and hypotonia were important in the early period, while dysphagia, ventilator dependence, and functional status became important in the long-term. A previous study with 169 patients with DM1 had shown that over half the number reported swallowing problems, whose major contributor seemed to be muscular weakness. Further, researchers found that swallowing abnormalities may be present even if only a few symptoms were reported, or severity of the disease was not much pronounced. ${ }^{13)}$ Therefore, serial check-ups for swallowing may be warranted in clinical followup visits for patients with DM1. Furthermore, although pulmonary function impairment is relatively slow in patients with DM1, compared to that in patients with other neuromuscular disorders, we need to carefully assess respiratory symptoms and routinely perform screening tests since respiratory impairment is a major cause of death among patients with DM1. ${ }^{14)}$ Therefore, although all the symptoms of DM1 are important for such a variable disease, longitudinal monitoring of certain clinical variables is required for affected individuals.

Individuals with DM1 inherently present a variable genotype that is dependent on the number of CTG repeats in DMPK. In our study, we found that patients exhibited a wide range of CTG-repeat length, ranging from 100 to more than 2,000 repeats. However, on the basis of genetic subgrouping, and in contrast to our finding from clinical subgrouping, we found poor feeding in neonate as the only variable that was statistically significant when compared between the 2 genetically defined subgroups. In contrast, a previous study had shown that patients with DM1 along with muscular weakness or dysfunction of the central nervous system also harbored larger CTG expansions compared to those without either symptom. ${ }^{10}$ Furthermore, many studies have reported that age of onset was in- versely correlated with the CTG repeat length ${ }^{10,11)}$; however, others argued that the correlation between age of onset and CTG repeat length was only significant for patients with small expansions. ${ }^{15,16)}$ In our current study, we found no evidence of association between the length of CTG repeats and age of onset, although all of the patients from our cohort were less than 15 years of age. Collectively, these findings demonstrate the challenges involved in genotypephenotype correlations. If age of onset and CTG repeat-length were inversely correlated, we would expect our findings, based on genetic subgrouping, to be similar to that of clinical subgrouping, which had shown evidence of association. Admittedly, in addition to the scarcity of the disease, our findings may not be generalizable due to the small number of patients evaluated, as well as, the fact that they were all under 15 years of age. Nevertheless, we cannot rule out the possibility of having no correlation between these factors at all, or of such associations being population-specific. In addition, since this is a retrospective study, there may be biases or errors in the medical records that may affect our study outcomes. Thus, further studies are warranted with a larger group of well-characterized patients.

Undoubtedly, a genetic approach is important for diagnosis since clinical symptoms of DM are not always specific; however, in reality, most diagnostic approach of DM1 is based on clinical symptoms as well, since it is necessary to make diagnostic estimates using several clues, unless a family history has been determined or confirmatory genetic testing is performed. In other words, clinical suspicion is the first step in diagnosis before confirmatory examinations, such as genetic tests, are performed. De Antonio et al. ${ }^{12)}$ had stated that age of onset and clinical form may be the key criteria in the design of clinical trials, when considering DM1 health management and research. Similarly, it is important to detect clinical clues from patients, including age of onset, and to know what characteristics to look for. Such efforts help in prognosis and preparation of proper management approach tailored for each patient; these could not be achieved simply from the number of CTG repeats.

Since DM1 has variable phenotypes and genotypes, there is no typical natural course or established management guidelines for patients with DM1. Serial examinations to detect newly developed abnormal signs and symptoms, for early treatment, need to be performed. Although some studies have recommended a series of examinations, they are general screening tools that are not based on individual parameters from patients. ${ }^{17,18)}$ For example, annual slit lamp examination of the lens (cataracts), pulmonary function test (respiratory failture), polysomnography (central/obstructive apnea), electrocardiogram (conduction disorder) and periodic thyroid function test (thyroid dysfunction), echocardiogram or cardiac magnetic resonance imaging (cardiomyopathy) are recommended. Therefore, several studies, such as PhenoDM1, ${ }^{19)}$ are underway to unravel the natural course of DM1 and achieve better outcomes. It is through these studies that a concrete and distinct protocol for the management of DM1 may be established, and many clinical features 
will play an important role in this process.

To summarize, we demonstrate the advantage of evaluating clinical variables through subgrouping in our small cohort of patients with DM1. Since DM is a rare disease, large prospective studies are difficult to perform; however, more large-scale studies are needed to develop individualized management protocols, based on the natural course of the disease and each patient's clinical characteristics; proper subgroup analyses, as in this study, will contribute to achieve this important goal for patients with DM1.

\section{Conflicts of interest}

No potential conflict of interest relevant to this article was reported.

\section{Acknowledgments}

The authors are grateful to all staff members, doctors, and statistical consultants who were involved in this study.

\section{References}

1. De Vivo DC, Ryan MM, Jones HR, Darras BT. Neuromuscular disorders of infancy, childhood, and adolescence: a clinician's approach. 2nd ed. Amsterdam: Academic Press, 2014.

2. Musova Z, Mazanec R, Krepelova A, Ehler E, Vales J, Jaklova R, et al. Highly unstable sequence interruptions of the CTG repeat in the myotonic dystrophy gene. Am J Med Genet A 2009;149A:1365-74.

3. Harper PS, Brook JD, Newman E. Myotonic dystrophy. 3rd ed. London: WB Saunders, 2001.

4. Bundey S, Carter CO, Soothill JF. Early recognition of heterozygotes for the gene for dystrophia myotonica. J Neurol Neurosurg Psychiatry 1970;33:279-93.

5. Pizzuti A, Friedman DL, Caskey CT. The myotonic dystrophy gene. Arch Neurol 1993;50:1173-9.

6. Mahadevan M, Tsilfidis C, Sabourin L, Shutler G, Amemiya C, Jansen
G, et al. Myotonic dystrophy mutation: an unstable CTG repeat in the 3' untranslated region of the gene. Science 1992;255:1253-5.

7. Brook JD, McCurrach ME, Harley HG, Buckler AJ, Church D, Aburatani $\mathrm{H}$, et al. Molecular basis of myotonic dystrophy: expansion of a trinucleotide (CTG) repeat at the 3' end of a transcript encoding a protein kinase family member. Cell 1992;68:799-808.

8. Arsenault ME, Prévost C, Lescault A, Laberge C, Puymirat J, Mathieu J. Clinical characteristics of myotonic dystrophy type 1 patients with small CTG expansions. Neurology 2006;66:1248-50.

9. Harley HG, Rundle SA, MacMillan JC, Myring J, Brook JD, Crow S, et al. Size of the unstable CTG repeat sequence in relation to phenotype and parental transmission in myotonic dystrophy. Am J Hum Genet 1993;52:1164-74

10. Kim SY, Kim JY, Kim GP, Sung JJ, Lim KS, Lee KW, et al. Molecular and clinical characteristics of myotonic dystrophy type 1 in koreans. Korean J Lab Med 2008;28:483-92.

11. Kahrizi K, Moradin N, Azimian M, Shojasaffar B, Alavi K, Nafiisi S, et al. Genotype-phenotype correlations in Iranian myotonic dystrophy type I patients. Iran Rehabil J 2010;8:8-12.

12. De Antonio M, Dogan C, Hamroun D, Mati M, Zerrouki S, Eymard B, et al. Unravelling the myotonic dystrophy type 1 clinical spectrum: a systematic registry-based study with implications for disease classification. Rev Neurol (Paris) 2016;172:572-80.

13. Willaert A, Jorissen M, Goeleven A. Swallowing dysfunction in myotonic dystrophy: a retrospective study of symptomatology and radiographic findings. B-ENT 2015;11:249-56.

14. Thil C, Agrinier N, Chenuel B, Poussel M. Longitudinal course of lung function in myotonic dystrophy type 1. Muscle Nerve 2017;56:816-8.

15. Hamshere MG, Harley H, Harper P, Brook JD, Brookfield JF. Myotonic dystrophy: the correlation of (CTG) repeat length in leucocytes with age at onset is significant only for patients with small expansions. $\mathrm{J}$ Med Genet 1999;36:59-61.

16. Savić D, Rakocvic-Stojanovic V, Keckarevic D, Culjkovic B, Stojkovic 0, Mladenovic J, et al. 250 CTG repeats in DMPK is a threshold for correlation of expansion size and age at onset of juvenile-adult DM1. Hum Mutat 2002;19:131-9.

17. Kurihara T. New classification and treatment for myotonic disorders. Intern Med 2005;44:1027-32.

18. Smith CA, Gutmann L. Myotonic dystrophy type 1 management and therapeutics. Curr Treat Options Neurol 2016;18:52.

19. Hanns L, Chris T. PhenoDM1 - Myotonic Dystrophy type 1 (DM1) deep phenotyping to improve delivery of personalised medicine and assist in the planning, design and recruitment of clinical trials. Clinical Trials.gov. NCT02831504. Bethesda (MD): U.S. National Library of Medicine, 2016 